\title{
Literatura em combate: a ficção de Rubem Fonseca nos anos 70
}

\author{
Luciana Paiva Coronel*
}

Resumo: Nos anos 70, transcorridos sob a vigência do AI-5, Rubem Fonseca produziu uma literatura contestadora de teor 'marginal', marcada pelo embate com a censura ditatorial e também com a crescente indústria cultural. Cada um dos três livros publicados na década acirra, por meio da metaficção de sua forma narrativa, a tensão existente entre escritor e sociedade, constituindo um discurso ficcional problematizador do ufanismo patriótico disseminado então pela propaganda governamental.

\begin{abstract}
During the 70's when the country was under the law of AI-5 (institutional act n. 5), Rubem Fonseca produced an insurgent literature with a 'marginal' character, defined by the struggle against the dictatorial censorship and also against the growing cultural industry. Each one of the three books issued during this decade stirs up, through the metaficcion of his narrative form, the tension existing between writer and society, which constitutes a fictional speech that questions the patriotic pride, which was then disseminated by the government propaganda.
\end{abstract}

Palavras-chave: Rubem Fonseca; Contos; Metalinguagem; Anos 70; Teor marginal.
Keywords: Rubem Fonseca; Short stories;

Metalanguage; The 70's; Marginal character.

Os anos 70 constituíram "o mais duro período da mais duradoura das ditaduras nacionais" (Gaspari, 2002). Ao mesmo tempo, foi a época das alegrias da Copa do Mundo de 1970, do aparecimento da TV em cores, das inéditas taxas de crescimento econômico e de um regime de pleno emprego - período este conhecido como o do "milagre brasileiro". A euforia do 'milagre' coincidiu paradoxalmente com os 'anos de chumbo', instaurados pelo AI-5 em dezembro de 1968 .

A utopia do 'Brasil grande' foi construída na época via televisão, via linguagem do espetáculo, numa circunstância histórica bastante específica, marcada pelo fechamento político e pelo estímulo governamental ao crescimento do mercado de bens simbólicos no país. Renato Ortiz compreendeu muito bem a dinâmica compensatória atribuída pelo poder ditatorial ao consumo de produtos culturais de massa:

\footnotetext{
Os aspectos de difusão e de consumo dos bens culturais aparecem assim como definidores da política do Estado, a eles se associa ainda a idéia de 'democracia'. O Estado seria democrático na medida em que procurasse incentivar os canais de distribuição dos bens culturais produzidos. O mercado, enquanto espaço social onde se realizam as trocas e o consumo, torna-se o local por excelência, no qual se exerceriam as aspirações democráticas. (ORTIZ, 1994, p. 116)
}

\footnotetext{
* Doutora em Literatura Brasileira pela USP.
} 
A retórica patriótica do 'País que vai pra frente' foi, assim, cimentada pelos meios de comunicação de massa, sobretudo pela televisão, que fornecia a uma população politicamente amordaçada os componentes básicos da identidade nacional, que convinha aos donos do poder construir. Maria Rita Kehl, falando especificamente sobre a rede Globo, considerada "a síntese da televisão brasileira na década de 70" (KEHL, 1979, p. 6), afirmou:

O Padrão-Globo de qualidade que se firmou sobretudo a partir de $73 \mathrm{com}$ a chegada da televisão colorida é incompatível com a estética do subdesenvolvimento criada por produtores culturais de esquerda - os teatros Arena e Oficina (considerando evidentemente as diferenças entre as suas propostas), o CPC da União Nacional dos Estudantes, os cineastas do Cinema Novo. A opulência visual eletrônica criada pela emissora contribuiu para apagar definitivamente do imaginário brasileiro a idéia de miséria, de atraso econômico e cultural; e essa imagem glamourizada, luxuosa, ou na pior das hipóteses antisséptica [...] contaminou a linguagem visual de todos os setores da produção cultural e artística que se propõem a atingir o grande público (p. 12).

Quando a 'euforia milagreira' parece entrar em fase de esgotamento, o governo fardado lança, em 1975, o I Plano Nacional de Cultura, com vistas a incidir com mais evidência na cena cultural brasileira. Através de uma política de incentivos às variadas produções artísticas e culturais, a meta era complementar a atividade inibitória da censura com ações que estimulassem (e direcionassem em algum sentido) a produção artística.

O cenário cultural assim configurado combina, portanto, repressão, cooptação e mesmo controle do Estado sobre o processo cultural. Referindo-se a tal período, Flávio Aguiar comenta: "De um lado, o governo mantinha a tesoura afiada e alerta; de outro, acenava com o cifrão" (AGUIAR, 1997, p. 14).

É claro que somente recebiam verbas governamentais produções condizentes com as expectativas do Estado em relação à esfera da cultura, identificadas no mais das vezes com a possibilidade de agradar um grande público e viabilizar, assim, o consumo de massa. Diz a respeito Renato Ortiz:

Poder-se-ia pensar que esta ideologia voltada para o público consumidor fosse característica de uma arte dispendiosa como o cinema, porém, quando Gustavo Dahl enuncia que 'mercado é cultura', sem o saber ele expressa uma realidade que transcende a esfera cinematográfica e que se refere ao domínio cultural como um todo, ao Espírito de uma época. (ORTIZ, 1994, p. 114)

As três obras de Rubem Fonseca dos anos 70 surgirão, portanto, no interior de um cenário cultural marcado pela hegemonia da arte de cunho comercial, que busca o público a qualquer custo. É exatamente no interior de tal contexto que o teor 'marginal' das obras deve ser compreendido. Heloisa Buarque de Hollanda - realizando uma espécie de balanço da produção cultural da década - define os anos 70 como marcados exatamente pela perda do poder contestatório das artes, tanto em termos estéticos quanto políticos: 
As artes plásticas sofrem um boom de mercado com os leilões e a bolsa de arte determinando sua produção, que, ao transformar-se preponderantemente em rentável negócio, perde muito a sua vitalidade crítica e praticamente deixa de interessar os setores da juventude universitária. Por sua vez, o teatro empresarial encontra um ótimo ambiente para as reluzentes e pasteurizadas super-produções e o cinema começa a assumir definitivamente sua maturidade industrial. Vinga portanto, a ideologia da competência, do padrão técnico e dos esquemas internacionalmente consagrados pela indústria cultural. (HOLLANDA, 1981, p. 91).

Zuenir Ventura, em artigo publicado no início da década, reitera a acomodação descrita por Heloísa Buarque e cunha a expressão 'vazio cultural' para caracterizar o período em que "a quantidade suplanta [...] a qualidade, desaparece [...] a temática polêmica e a controvérsia da cultura" (GASPARI; HOLLANDA; VENTURA, 2000, p. 41).

Rubem Fonseca estréia na década de 70 publicando seu primeiro romance, $O$ caso Morel, em 1973. Fragmentário, o romance mostrava-se dotado de forte teor metaficcional, decorrente da voz narrativa de Paul Morel, artista plástico preso por acusação de assassinato, e portador de uma infinidade de referências intertextuais, a maioria das quais referentes a autores e obras identificados com a problemática do erotismo.

O teor 'marginal' da narrativa advém, em parte, da identificação gradualmente conformada entre a figura do escritor (Vilela) e a do bandido (Morel), um artista de vida promíscua e transgressor da moral e dos bons costumes. Em parte também origina-se da crueza com que é representada a vida sexual do protagonista. O todo que reúne as vozes de ambos os personagens entrecortadas por citações as mais variadas constitui exemplo de arte grosseira, suja, agressiva. Exemplo de uma ficção em combate com a totalidade da vida social de que se originava.

Para confrontar e mesmo a denunciar a esterilidade da cena cultural circundante, $O$ caso Morel apresenta o bandido como herói, traço peculiar da cultura da época, sobretudo da vertente cultural identificada com a contracultura. Encarnando os ideais de liberdade e rebeldia, o bandido foi no final dos anos 60 tema de filme (O bandido da Luz vermelha, de Rogério Sganzerla) e também de obra plástica (a frase-estandarte de Hélio Oiticica: "seja marginal, seja herói”).

Ambas as produções, surgidas em 1968, encarnavam valores e predisposições que se tornariam muito peculiares à década seguinte. Ambas homenageavam bandidos reais, figuras em foco na imprensa naquele contexto, o que não ocorria com o romance de Rubem Fonseca, no qual o elemento transgressor era um personagem ficcional, locus imaginário de autonomia e liberdade, quando a situação real dos produtores culturais era marcada pelas restrições oriundas seja da censura, seja do mercado. 
Essas duas espécies de cerceamento comparecem no corpo estilhaçado de $O$ caso Morel: o protagonista tem sua obra erótica, Vênus RB, na qual pênis, vaginas e também cifrões comparecem como peças de uma ignição maior, apreendida pela censura por atentado à moral e aos bons costumes e também dedica-se, como estratégia de sobrevivência material, à atividade de 'fotógrafo-gigolô' de comerciais publicitários, segundo suas próprias palavras.

O bandido-transgressor constitui, assim, a figura por meio da qual Fonseca possivelmente vingue-se simbolicamente da acomodação reinante no país, tanto em termos políticos quanto estéticos. Seguindo essa perspectiva, o personagem Morel condena Vilela, personagem escritor de vida pacata, pelas atividades 'imundas' às quais se dedica: "Polícia, advogado, escritor. As mãos sempre sujas" (FONSECA, 1995, p. 27).

Artista bastante incômodo e inconformista incorrigível, Morel se mostra ao longo do enredo insatisfeito tanto com a arte-mercadoria do comercial de cerveja e quanto com a arte tradicional, fadada, segundo ele, a perdurar empoeirada em museus distantes da agitação da vida da metrópole. Tampouco a perspectiva da vanguarda, identificada com a obra Conexão [de esgoto] lhe agrada: "uma merda" segundo suas próprias palavras (p. 36). O esteticismo gratuito da montagem de canos revela-se também incapaz de produzir sentido como arte.

A narrativa de Morel é, como sua pintura, composta em boa medida por fragmentos avulsos justapostos sem nexos explicativos ou amarrações de qualquer espécie, mostrando-se capaz de problematizar a vida moderna por meio da representação da figura do artista 'marginal' que não transige.

$\mathrm{Na}$ medida em que considera o leitor cúmplice pela situação vigente, seja pela acomodação conformista, seja pela alienação conveniente, Fonseca trata de construir no terreno da literatura uma espécie de apologia da forma de vida do elemento fora da lei, glorificado em razão de sua ousadia no descumprimento de leis de cuja observância resulta a vida pacata e covarde dos demais.

Rubem Fonseca acirra no romance de 1973 a tensão existente entre o artista e a sociedade. Ainda que não tenha sido encontrada nenhuma prova irrefutável para incriminá-lo, o delegado encarregado do caso admite que a prisão de Morel faz-se necessária:

"É evidente que o juiz tinha que decretar', diz Vilela. 'Morel é artista e assim, por definição, suspeito; além do mais, promíscuo sexualmente, o que faz dele, no mínimo, uma ameaça. Aposto que a fiança dele foi negada com base no parágrafo quarto do artigo trezentos e vinte e três - a incaucionabilidade dos vagabundos”. (FONSECA, 1995, p.108).

Por considerar os atos de Morel "inconciliáveis com a possibilidade de sua inocência" (p.109), o policial admite estar condenando o artista não pelo crime da morte da namorada, mas por sua conduta desajustada. A identificação do escritor Vilela com o elemento marginal 
Morel constitui, assim, uma opção estética plena de desdobramentos ideológicos e políticos. Espécie de peculiaridade cultural do período.

A temática marginal ficcionalmente elaborada por Fonseca será retomada nos próximos livros, os dois de contos, Feliz Ano Novo, de 1975 e O cobrador, de 1979, nos quais adquirirá novos e interessantes desdobramentos metaficcionais, tornando-se o bandido progressivamente mais próximo do homem de letras e este cada vez mais identificado com as condutas ilícitas daquele.

Acirra-se o acento marginal a partir de Feliz Ano Novo, no interior do qual o elemento outsider deixa de ser um homem branco, de classe média e intelectualizado, passando a identificar-se com o bandido assaltante no conto que dá título ao volume, ainda que este apresente certos traços que o aproximam sutilmente daquele.

Há também um artista propriamente dito no livro. Trata-se do autor anônimo do conto "Intestino grosso", o qual, sem deixar de identificar-se com a temática erótica, define-se por meio da afinidade com o universo do crime: "Fiquei entre escritor e bandido", diz o personagem em entrevista a respeito de suas opções de carreira.

O personagem, chamado simplesmente "Autor" pela voz narrativa, não tem a intenção de agradar a quem quer que seja. Cobrando por palavra e lançando impropérios a todos os lados, o "Autor" constitui a encarnação do artista maldito, na esteira do que representara Paul Morel no livro anterior. Diz o personagem a certa altura: “A metáfora surgiu por isso, para os nossos avós não terem de dizer - foder. Eles dormiam com, faziam amor (às vezes em francês), praticavam relações, congresso sexual, conjunção carnal, coito, cópula, faziam de tudo, só não fodiam (p. 463).

Aludindo possivelmente ao próprio estilo muito cru e nada metafórico, o autor mineiro defende a idéia de que a prática da arte esteja ligada à "desexcomungação do corpo", que requer investigações acerca das obscuras relações entre corpo e mente. O “Autor", assim como Fonseca, refere ter intitulado uma de suas obras com o nome de um órgão corporal imediatamente relacionado à função excretora, o intestino.

A dureza do estilo ficcional criado é justificada ainda no interior do conto em virtude da necessidade de contraposição estética e ideológica à linguagem superficial e inócua da televisão, veículo maior da integração nacional desde os anos 70 . O teor metaficcional da mesma é evidente:

Entre meus leitores existem os que são tão idiotas quanto os legumes humanos que passam todas as horas de lazer olhando televisão. Eu gostaria de dizer que a literatura é inútil, mas não é, num mundo em que pululam cada vez mais técnicos. Para cada Central Nuclear é preciso uma porção de poetas e artistas, do contrário estamos fudidos antes mesmo da bomba explodir. 
$[\ldots]$

Eu nada tenho a ver com Guimarães Rosa, estou escrevendo sobre pessoas empilhadas na cidade enquanto os tecnocratas afiam o arame farpado. (FONSECA, 1994, p. 468)

A necessidade mencionada pelo autor de renovação da linguagem literária a fim de acompanhar os tempos que corriam, tempos de tecnocracia e de massas humanas empilhadas em metrópoles violentas requer, em sua visão, a superação dos clássicos da prosa de ficção moderna: "Odeio o Joyce, odeio todos os meus antecessores e contemporâneos" (FONSECA, 1994, p. 466).

Apesar da repulsa assumida em relação à literatura do passado e também do presente, o Autor refere com boa dose de ironia uma infinidade de escritores, como Stendhal, Proust, T.S.Elliot, entre outros, contando ainda possuir uma biblioteca de cinco mil volumes, quase todos já lidos. João Luiz Lafetá chamou a atenção para o paradoxo aí contido:

para representar o centro da cidade, cheio de anúncios coloridos em néon e barulho de automóveis, foi-lhe necessário não apenas mergulhar na experiência da vida urbana, mas também atravessar a pilha dos 'cinco mil' volumes. Desde os primeiros livros, seus contos estão cheios de referências explícitas ou de alusões à literatura, à música, à pintura, à filosofia etc. Em certo sentido, são textos fortemente intelectuais - e este não é o menor dos paradoxos porque, por outro lado, ele dá a impressão de sempre estar fazendo pouco caso do mundo da cultura. (LAFETÁ, 2000, p. 122)

Esta segunda obra da década apresenta um padrão narrativo mais tradicional, ainda que à perspectiva da transgressão moral de $O$ caso Morel acrescente-se agora a da subversão social, por meio dos bandidos em situação de assalto no conto "Feliz ano novo".

Narrado pela dicção chula de um bandido assaltante de rua, o conto é o paradigma da estética marginal no interior da obra de 1975. A voz do elemento fora-da-lei conforma mais uma vez uma espécie de resistência simbólica ao processo em curso de crescimento das publicações voltadas ao mero entretenimento.

As madames granfas tão todas de roupa nova, vão entrar o ano novo dançando com os braços pro alto, já viu como as branquelas dançam? Levantam os braços pro alto, acho que é pra mostrar o sovaco, elas querem mesmo é mostrar a boceta mas não têm culhão e mostram o sovaco. Todas corneiam os maridos. Você sabia que a vida delas é dar a xoxota por aí? (FONSECA, 1994, p. 365-366).

A forma suja, marcada pela oralidade da voz de um bandido se faz presente igualmente em $O$ cobrador, de 1979. O último livro da década unifica as duas ênfases da marginalidade já apresentadas, a transgressão da moral e a subversão social, acrescentando às mesmas uma terceira modalidade de enfrentamento em relação à sociedade, identificada com a dimensão política e representada por meio do personagem que, não bastasse ser poeta e bandido, adere à luta armada tornando-se guerrilheiro.

Não há que agradar o público. Rubem Fonseca parte para o ataque unificado da acomodação social, moral e política que viceja no solo da classe média brasileira, tornando 
sua ficção áspera, obscena e mais violenta do que nunca. Recupera-se e atualiza-se a representação do escritor transgressor da moral tradicional na narrativa eminentemente metaficcional "Pierrô na caverna", e também o discurso do bandido miserável, cujo teor metaficcional apenas sugerido em "Feliz ano novo" torna-se inequívoco e assumido em "O cobrador".

No caso deste último, contudo, acentua-se a convicção do personagem em relação à função dos ataques dirigidos aos elementos bem-posicionados da estrutura social. Ele se conscientiza da missão a ser cumprida e passa a planejar grandes atentados com vistas a mudar o mundo. Fecha-se um ciclo de sua vida, o justiceiro vira guerrilheiro, e também da ficção literária de Rubem Fonseca, que nos anos 80 procura estabelecer outras formas de interação com a sociedade que não a agressão feroz que o livro em discussão leva às últimas conseqüências.

Narrado por um escritor em momento de crise criativa, "Pierrô na caverna" realiza uma espécie de dissimulação dos aspectos propriamente literários da sua forma. Atestam o fato as reiteradas colocações da voz narrativa, que apontam no sentido da mera transcrição dos fatos vividos:

Carrego um gravador a tiracolo. Apenas quero falar, e o que eu disser não será passado jamais para o papel, e assim não tenho necessidade de buscar o estilo requintado que os críticos tanto elogiam e que é apenas um trabalho paciente de ourivesaria. Não sabendo como as palavras se posicionam no papel perco a noção da sua velocidade e coesão, da sua compatibilidade. Mas isso não interferirá com a história. Havia alguém me vigiando atrás da porta... (FONSECA, 1994, p.477)

Além de conformar uma crítica aos procedimentos literários usuais, bem como aos críticos que os legitimam, o conto, no entanto, não deixa de autoproblematizar sua forma, constituindo uma narrativa que se apresenta ao leitor na condição de despretensiosa gravação, que jamais daria origem a um texto escrito e literário.

Rubem Fonseca converte a forma ficcional em instrumento de discussão das relações do autor com seu público, oferecendo aos seus efetivos leitores um conto cujo narrador é um autor que não deseja assumir os riscos e a responsabilidade decorrente do papel de narrar, aginndo com um descompromisso literário pleno de decorrências formais e pragmáticas.

Entre estas, pode-se apontar a oralidade e a espontaneidade da forma, aspectos, no entanto, que se fazem acompanhar de recursos compositivos complexos, como as inúmeras referências intertextuais e as constantes indagações metaficcionais, traços centrais da identidade ficcional do autor:

Meu prestígio de escritor e minhas pretensões exigem que a novela seja uma alegoria sobre a ambição, a soberba e a impiedade. Agora pergunto: para quem armo eu continuamente essa empulhação de seriedade e profundeza? Os meus contemporâneos? Mas desprezo todos, não 
tenho um só amigo e nunca vejo os conhecidos, a única vez que estive pessoalmente com meus editores foi há três anos atrás, entendo-me com eles por meio de cartas. Os meus contatos freqüentes são apenas com as mulheres com quem mantenho relações amorosas. Mas também não é para elas que teço minha rede de mentiras, hipérboles e subterfúgios, não é a sua admiração que quero. [...] No entanto estou aqui contando tudo para um objeto eletrônico, quadrado, movido a pilha. Mas jamais seria capaz de escrever sobre isso. Escreverei sobre a criação do deserto na Amazônia pelas mãos predatórias do homem, sobre o terror atômico, sobre as injustiças sociais e econômicas. Mas o papel que espere por essas verdades transcendentais mais um pouco. Agora quero continuar falando, daqui a pouco talvez esse brinquedinho me canse. (FONSECA, 1994, p. 484)

Afloradas em meio ao desabafo de um autor que se despe dos paramentos de escritor, destituindo igualmente sua ficção dos paramentos de literatura, colocações metalinguiísticas como esta apontam o choque existente entre os assuntos dos quais o autor trata e aqueles que ele pensa que deveria tratar, ou que ele julga que o público espera que ele trate: os grandes problemas que afetam o planeta.

Por meio do subterfúgio de não atribuir ao discurso proferido o caráter de ficção literária, o personagem pode tratar dos assuntos que têm premência em sua mente, deixando os 'grandes temas' de lado. Não deixa de haver nessa auto-exclusão do terreno da literatura o reconhecimento de uma espécie de 'sem-lugar' para o seu discurso incômodo e, também, como sucedâneo disso, a noção de que o fazer literário requer em alguma medida a problematização de algum âmbito da realidade.

O desabafo do personagem escritor gira em torno do seu desejo obsessivo por Sofia, uma menina de doze anos. As inúmeras referências eruditas presentes na narrativa são decorrências dessa atração perturbadora e dizem respeito a autores que trataram do assunto em suas obras: Malle, Nabokov, Dostoiévski e Kierkgard.

Essas referências surgem como um amparo, inserindo o personagem incorrigivelmente solitário em um campo maior, permitindo que ele rompa o isolamento no qual a própria má consciência o colocara e possa reintegrar-se, nem que seja no time dos artistas identificados com a modalidade de transgressão que o protagonista efetivamente pratica.

É possível que o escritor pedófilo, personagem que desrespeita um dos maiores tabus da civilização, mostrando uma conduta aberrante e monstruosa, constitua mais uma alegoria do escritor desajustado no meio em que vive, no qual não lhe parece minimamente interessado em integrar-se, sendo, inclusive, um apologista da desordem e da rebeldia.

Os versos primários de "O cobrador", por sua vez, verdadeiras imprecações àqueles que se beneficiam com as injustiças sociais, só parecem constituir arte para seu autor, que se diz poeta, mas concebe a poesia essencialmente como arma de luta, pondo a palavra em ação apenas para expressar seu ódio: 
Os ricos gostam de dormir até tarde/ apenas porque sabem que a corja/tem que dormir cedo para trabalhar de manhã/ Essa é mais uma chance que eles/ têm de ser diferentes:/ parasitar,/ desprezar os que suam para ganhar a comida,/dormir até tarde,/ tarde/ um dia/ ainda bem/ demais./ [...]

A História é feita de gente morta/ e o futuro de gente que vai morrer" (FONSECA, 1994, p. 494).

Em um contexto cultural como o dos anos 70 , no qual o filão literário de maior sucesso identificava-se com a literatura-verdade em suas várias formas de expressão, os romance-reportagem, os textos confessionais, os depoimentos político-bibliográficos, o memorialismo, Rubem Fonseca, na contra-mão do mercado, cria uma literatura excessivamente auto-referenciada e indigesta.

Os dois narradores citados, sendo artistas, recusam-se a exercer o papel tradicional de autores; um porque demasiado atormentado por obsessões pessoais, outro porque demasiado empenhado em realizar atos de reparação social. Para este, aliás, os bárbaros assassinatos dos ricos constituem suas maiores realizações 'poéticas'.

Se, por um lado, em "Pierrô na caverna" o escritor adentra o mundo do crime através de infração de ordem sexual tão brutal quanto assumida, por outro, em "O cobrador", o bandido adentra o mundo das letras, apresentando-se como poeta e efetivamente dividindo-se entre a confecção de poemas e a realização de crimes hediondos:

Levantei alto o facão, seguro nas duas mãos, vi as estrelas do céu, a noite imensa, o firmamento infinito e desci o facão, estrela de aço, com toda minha força, bem no meio do pescoço dele.

Ergui alto o alfange e recitei: Salve o Cobrador! Dei um grito alto que não era nenhuma palavra, era um uivo comprido e forte, para que todos os bichos tremessem e saíssem da frente. Onde eu passo o asfalto derrete" (FONSECA, 1994, p. 497).

A linguagem com que o 'cobrador' narra seus feitos bárbaros é despropositalmente rica, metafórica, desapegada poeticamente da contingência narrada e alçada a um plano mais elevado de expressão verbal. Trata-se de um personagem inverossímil, se tomado na condição de representação realista, que veio sendo delineado ao longo da década de $70{ }^{1}$

"Feliz Ano Novo" já reservara, como se viu, o papel de narrador a um bandido estranhamente instruído, que manifestava pelos moradores da casa assaltada e pelos programas de televisão um desprezo estranhamente fundamentado. Por meio desses traços inusitados, compartilhados com o personagem escritor, o bandido já possuía ali traços

\footnotetext{
${ }^{1}$ No filme Terra em transe, de 1967, Glauber Rocha já representava a sobreposição dos papéis de poeta e agente político, por meio do personagem Paulo, que reluta, mas termina por envolver-se com a política em sua modalidade institucional, candidatando-se nas eleições de Eldorado. É dele a frase "este povo, cuja tristeza apodreceu o sangue, precisa de morte mais do que se possa supor", muito próxima do ideário do cobrador. Incapaz de vencer os poderosos da região, o personagem, amargo e muito cético, profere ao final da trama uma espécie de epitáfio das próprias aspirações: "Poesia e política são demais para um homem só."
} 
alegóricos, afastando a ficção de Fonseca da perspectiva de uma prosa meramente documental, com a qual era, e ainda é, seguidamente confundida.

No conto de 1979, o bandido adquire um grau ainda mais elevado de consciência histórica, fato que lhe permite compreender a situação de miséria e marginalidade em que vive não como insucesso pessoal, mas como decorrência de falhas no sistema de distribuição social das riquezas produzidas, que jamais o contemplou com o que quer que fosse:

A rua cheia de gente. Digo, dentro da minha cabeça e às vezes para fora, está todo mundo me devendo! Estão devendo comida, buceta, cobertor, sapato, casa, automóvel, relógio, dentes, estão me devendo. Um cego pede esmolas sacudindo uma cuia de alumínio com moedas. Dou um pontapé na cuia dele, o barulhinho das moedas me irrita. Rua Marechal Floriano, casa de armas, farmácia, banco, china, retratista, Light, vacina, médico, Ducal, gente aos montes. De manhã não se consegue andar na direção da Central, a multidão vem rolando como uma enorme lagarta ocupando toda a calçada. (FONSECA, 1994, p. 492)

Opondo-se ao pedinte, que não afronta nada nem ninguém e ainda vive às custas de compaixão, o protagonista refaz continuamente o rol das próprias carências, esforçando-se para deixá-lo completo, amostragem integral de necessidades tão antigas quanto desatendidas, que o estimulará a agir no sentido de buscar, ainda que tardiamente, algum tipo de reparação:

Tão me devendo colégio, namorada, aparelho de som, respeito, sanduíche de mortadela no botequim da rua Vieira Fazenda, sorvete, bola de futebol.

Fico na frente da televisão para aumentar meu ódio. Quando minha cólera está diminuindo e eu perco a vontade de cobrar o que me devem eu sento na frente da televisão e em pouco tempo meu ódio volta. Quero pegar um camarada que faz anúncio de uísque. (Fonseca, 1994, p. 493)

A televisão, vendendo sonhos de consumo inacessíveis, torna-se a fonte que alimenta a ira que move o "cobrador" à ação. Elemento outsider que perturba a paz daqueles que querem simplesmente seguir vivendo, o personagem alegoriza a figura do escritor e a força combativa da sua arte.

Ao longo da década de 70, como se viu, Rubem Fonseca elaborou uma forma ficcional agressiva, brutal. Por meio de diferentes personagens, o autor aproximou as figuras do escritor e do bandido, o que pode ser entendido enquanto resistência à acomodação estética que resultava da dupla atuação da censura e da força do mercado sobre o conjunto das produções artísticas.

A literatura nos anos 70 era para o autor um espaço de resistência e de combate, no qual narrava-se com brutalidade as cenas e situações que à televisão cabia esconder, um espaço no qual procurava-se desconstruir e confrontar a retórica do 'país que vai pra frente', da euforia patriótica da grandeza da Nação. 


\section{Referências}

AGUIAR, Flávio. A palavra no purgatório. São Paulo: Boitempo, 2002.

GASPARI, Elio. As ilusões armadas: a ditadura escancarada. 1.reimp. São Paulo: Cia das Letras, 2002.

GASPARI, Elio, HOLLANDA, Heloísa Buarque de, VENTURA, Zuenir. 70/80 Cultura em trânsito: da Repressão à Abertura. Rio de Janeiro: Aeroplano, 2000.

FONSECA, Rubem. Contos reunidos. São Paulo: Cia das Letras, 1994.

FONSECA, Rubem. O caso Morel. São Paulo: Cia. das Letras, 1995.

HOLLANDA, Heloísa Buarque de. Impressões de viagem: CPC, vanguarda e desbunde: 1960/1970. São Paulo: Brasiliense, 1981.

KEHL, Maria Rita. Um só povo, uma só cabeça, uma só nação. In: NOVAES, Adauto (Org). Anos 70 - Televisão. Rio de Janeiro: Europa, 1979. 